\title{
White matter hyper-intensity burden in ischemic stroke patients treated with mechanical thrombectomy
}

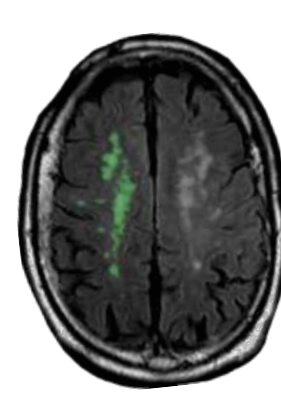

Grégoire BOULOUIS, MD; 1 Nicolas BRICOUT, MD;2 Wagih BENHASSEN, MD; ${ }^{1}$ Marc FERRIGNO, MD; 3 Guillaume TURC, PhD; ${ }^{4}$ Martin BRETZNER, MD; ${ }^{2}$ Joseph BENZAKOUN, MD; ${ }^{1}$ Pierre SENERS, PhD; ${ }^{4}$ Thomas PERSONNIC, MD; ${ }^{3}$ Laurence LEGRAND, MD; ${ }^{1}$ Denis TRYSTRAM, MD; 1 Christine RODRIGUEZ-REGENT, MD; ${ }^{1}$ Andreas CHARIDIMOU, PhD; ${ }^{5}$ Natalia S. ROST, MD-MPH; ${ }^{5}$ Serge BRACARD, MD; ${ }^{6}$ Charlotte CORDONNIER, PhD; 3 Catherine OPPENHEIM, PhD; ${ }^{1}$ Olivier NAGGARA, PhD; ${ }^{*}$ and Hilde HENON, PhD. ${ }^{3 *}$

${ }^{1}$ Neuroradiology department, ${ }^{4}$ Neurology Department, Paris Descartes University, INSERM U894, DHU Neurovasculaire, Sainte-Anne Hospital, Paris, France; ${ }^{2}$ Neuroradiology department, ${ }^{3}$ Université de Lille, Inserm U1171, Degenerative and Vascular Cognitive Disorders, CHU Lille, Department of Neurology 5 J. Philip Kistler Stroke Research Center, Department of Neurology, Massachusetts General Hospital and Harvard Medical School, Boston, MA, USA ${ }^{6}$ Neuroradiology department, Lorraine University, INSERM U1254 CHRU Nancy, France;

Introduction: We aimed to determine the influence of WMH burden on functional outcome, rate of symptomatic intracranial hemorrhage $(\mathrm{ICH})$ and procedural success in AIS patients treated by MT with current stentriever/aspiration devices.

Patients and Methods: Patients with AIS due to LVO from THRACE trial, and prospective cohorts from two academic comprehensive stroke centers treated with $\mathrm{MT}$, were pooled and retrospectively analyzed. WMH volumes were obtained by semi-automated planimetric segmentation and tested in association with the rate of favourable outcome (90 days functional-independence), substantial recanalization after MT, and symptomatic $\mathrm{ICH}$.

Results: A total of 496 subjects were included between 2015 and 2018 $(50 \%$ female, mean age 68.1 years \pm 15.0 , See Flowchart for details). Overall, 434 (88\%) patients presented with detectable $\mathrm{WMH}$ (mean: $4.93 \pm$ SD 7.7), See Table 1. Patients demonstrated increasingly worse outcomes with increasing WMH volumes (See Table 2). 57\% of patients in the $1^{\text {st }}$ quartile of $\mathrm{WMH}$ volume vs $28 \%$ in the $4^{\text {th }}$ demonstrated favourable outcome $(p<0.001$, see Figure). WMH severity was not associated with $\mathrm{sICH}$ rate (adjusted OR: 0,99 [0,93 - 1,04], $p=0.66$ ) nor did it influence recanalization success (adjusted OR:0,99 [0,96 - 1,02], $p=0.84)$.

\begin{tabular}{|c|c|c|c|c|}
\hline & $\begin{array}{c}\text { All patients } \\
(n=496)\end{array}$ & $\begin{array}{c}\text { Unfavourable } \\
\text { outcome ( } n=287)\end{array}$ & \begin{tabular}{|c|} 
Favourable \\
outcome ( $n=209)$
\end{tabular} & p value \\
\hline Female sex & $246(49,6)$ & $154(53,7)$ & $107(51,4)$ & 0,23 \\
\hline Age, years & $68,09 \pm 15,3$ & $72,04 \pm 14,38$ & $62,64 \pm 14,86$ & $<0,001$ \\
\hline mRs pre stroke $>2$ & $27(9,5)$ & $3(1)$ & $27(13)$ & $<0,001$ \\
\hline Diabetes Mellitus & $64(12,9)$ & $44(15,3)$ & $20(9,6)$ & 0,12 \\
\hline Hypertension & $289(58,3)$ & $190(66,2)$ & $99(47,6)$ & $<0,001$ \\
\hline Dyslipidemia & $187(37,7)$ & $112(39)$ & $75(36,1)$ & 0,76 \\
\hline I.V. tPA & $366(73,8)$ & $195(67,9)$ & $171(81.8)$ & $<0,001$ \\
\hline NIHSS & $16,43 \pm 5,98$ & $17,59 \pm 5,88$ & $14,83 \pm 5,77$ & $<0,001$ \\
\hline Blood Glucose level (g/l) & $1.32 \pm 0.44$ & $1,39 \pm 0,51$ & $1,22 \pm 0,3$ & $<0,001$ \\
\hline M1 occlusion & $374(75,4)$ & $206(71,8)$ & $168(80,4)$ & 0,007 \\
\hline DWI ASPECTs & $7.76 \pm 2,2$ & $7,4 \pm 2,37$ & $8,02 \pm 1,86$ & $<0,001$ \\
\hline Onset to groin puncture (h) & $3,75 \pm 1,2$ & $3,86 \pm 1,21$ & $3,61 \pm 1,11$ & 0,022 \\
\hline Substantial recanalization & $374(75,4)$ & $189(65,9)$ & $185(88,5)$ & $<0.001$ \\
\hline Symptomatic ICH & $39 / 478(8.2)$ & $36 / 276(13.0)$ & $3 / 202(1.49)$ & $<0.001$ \\
\hline FLAIR WMH Volumes (ml) & $4.93 \pm 7.7$ & $5.83 \pm 7.8$ & $3.7 \pm 7$ & $<0.001$ \\
\hline
\end{tabular}

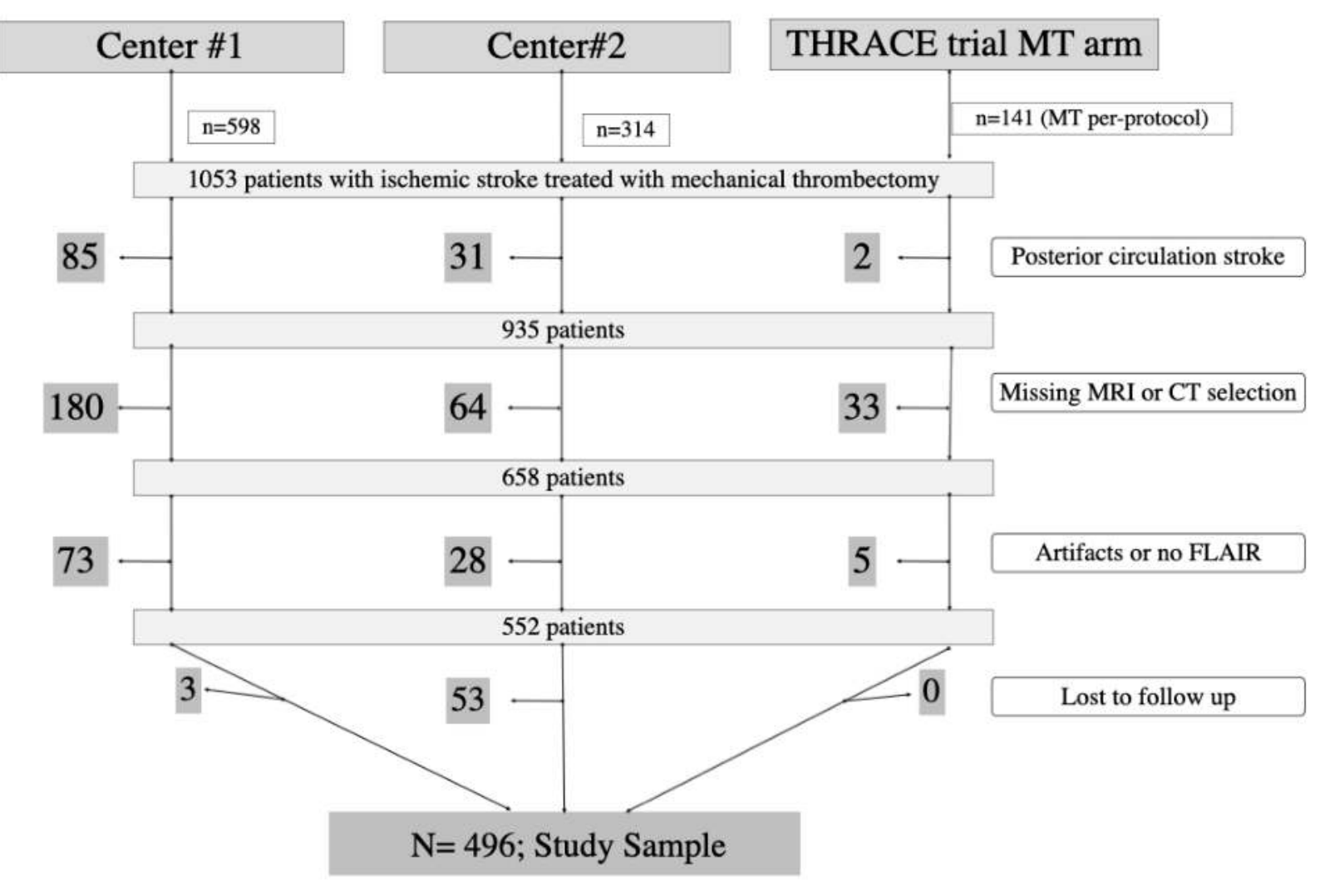

Flowchart: Details of patients' selection

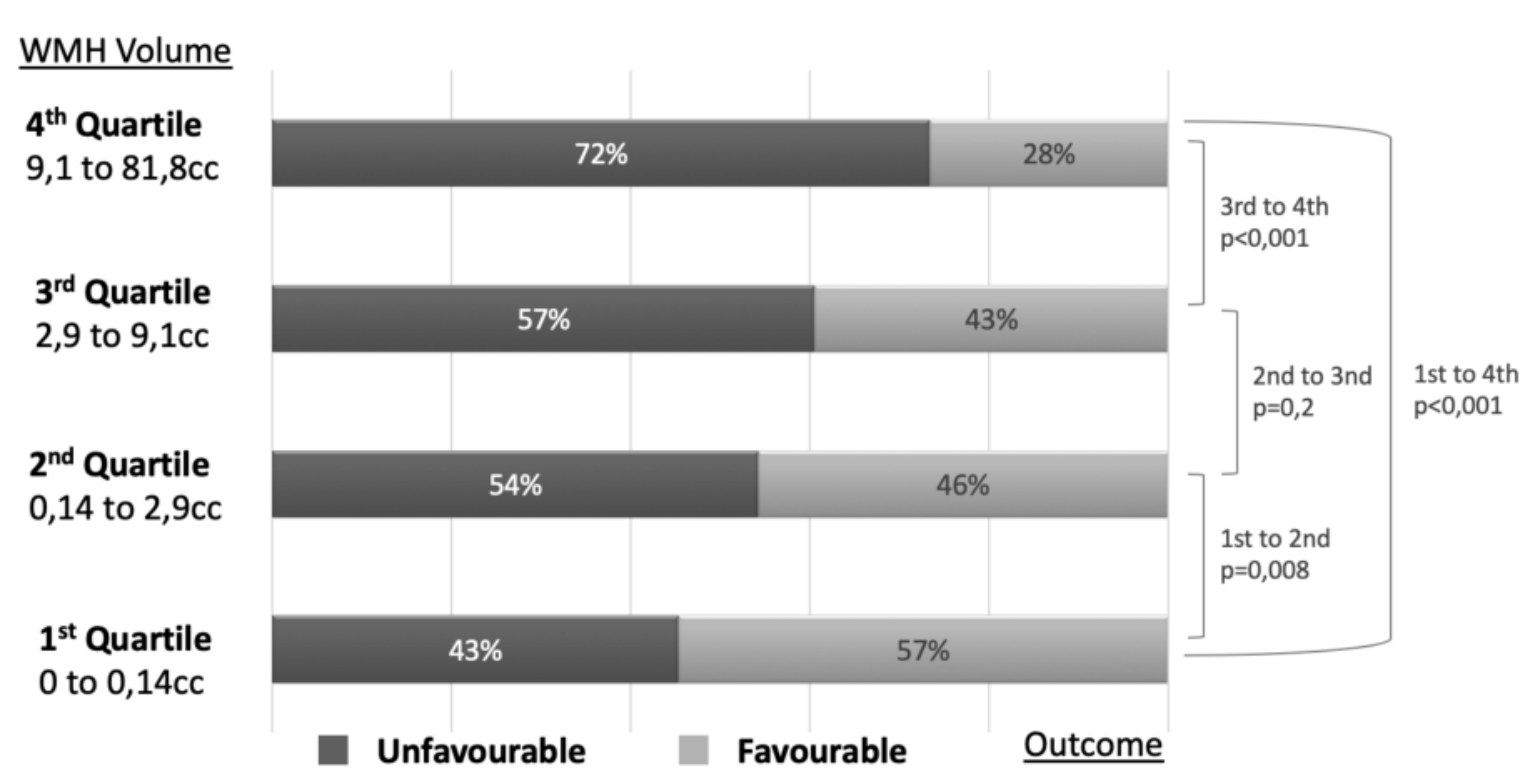

Figure: Outcome stratified per quartile of WMH volume

\begin{tabular}{|l|c|c|}
\hline & \multicolumn{2}{|c|}{ 90D mRs $>2(\mathrm{n}=284 / 496,57 \%)$} \\
\hline Variable & OR [95\%Cl] & $\mathrm{p}$ \\
\hline WMH Volume (per cc) & $1,05[1.01-1,06]$ & 0.014 \\
\hline
\end{tabular}

Table 2: Mutlivariable model adjusted for Age, Sex (Female), Hypertension, NIHSS, Blood Glucose g/l, ASPECTs, Occlusion site, i.v. tPA prior to MT, Onset to groin (hours), Substantial recanalization

Conclusion: Our study provides evidence that in patients with AIS due to LVO and high burden of WMH as assessed by pretreatment MRI, the safety (sICH) and efficacy (procedural success) profiles of MT are similar to those with lower WMH burden. Despite lower odds of favourable clinical outcomes, since over a quarter of patients in the highest WMH quartile experienced favorable 3 months outcome, WMH burden may not be a good argument to deny MT. ClinicalTrials.gov Identifier: NCT01062698 